\title{
Comparison between types of gastrostomy tubes. A literature review
}

\begin{abstract}
In order to assess which type of gastrostomy tube is the most indicated in a general parameter, a bibliographic review and analysis was carried out between scientific articles and books in order to understand the positive and negative sides of each model. From this, it is noted that there are clear individualities, in functional aspects, cost and contraindications. It was observed the importance of a trained professional to perform the best choice for the procedure.
\end{abstract}

Keywords: gastrostomy, botton tube, balloon tube, peg tube

\author{
Volume 6 Issue I - 202 I \\ João Alfredo Diedrich Neto,' Marcos \\ Orestes Gonçalves, ${ }^{2}$ Vinicius Beck da \\ Silveira, ${ }^{2}$ Eduarda Paitl Agostinho, ${ }^{2}$ Arthur \\ Freccia, ${ }^{2}$ Luize Cristine Dias, ${ }^{2}$ Matheus \\ Ferreira de Moraes $^{2}$ \\ 'Department of Gastrointestinal Surgery, Federal University of \\ Health Sciences of Porto Alegre, Brazil \\ ${ }^{2}$ Department of Medicine, Centro Universitário de Brusque - \\ UNIFEBE, Brazil
}

Correspondence: João Alfredo Diedrich Neto, Department of Gastrointestinal Surgery, Federal University of Health Sciences of Porto Alegre, Brazil, Email joaodiedrich@gmail.com

Received: December 20, 2020 | Published: January 25, 2021

\section{Introduction}

In 1839, Sedillott successfully performed gastrostomies on dogs, but failed to perform the same procedure on humans in 1846, with the death of three patients. Years later, in 1876, Verneoil did the first successful gastrostomy in humans. Since then, several technical modifications have been suggested, such as the Witzel technique, in 1891 , in which a subserous tunnel is made over the probe. ${ }^{1}$ Stamm. ${ }^{2}$ described one of the techniques most performed today and in the history of surgical gastrostomy, which consists of making a bag suture to invaginate the tube inserted in the stomach. ${ }^{3}$ In 1980, it was described by Gauderer et al. ${ }^{4}$ Percutaneous endoscopic gastrostomy, which has radically modified the gastrostomy preparation technique.

Gastrostomies are indicated for patients with an intact gastrointestinal tract but unable to receive adequate caloric intake orally for long term. Gastrostomy can also be indicated for gastric decompression in cases of severe gastroparesis and for inoperable intestinal obstructions. ${ }^{5}$ Currently, three gastrostomy techniques are described in the literature: percutaneous fluoroscopic gastrostomy, percutaneous endoscopic gastrostomy (PEG) and surgical gastrostomy.

\section{Research objectives}

Establish which is the best tube model for gastrostomy.

\section{Literature review}

In the early days of medical evolution, gastrostomy became a procedure in which, many times, made life possible. Therefore, several techniques had to be improved and developed in order to establish a minimally invasive and efficient therapy. In this sense, to perform a gastrostomy, you have, beforehand, several options of tubes.

The tubes specially manufactured for gastrostomy have two routes for infusion, a larger one for feeding, and the other smaller, for medications. A third one is used to inject liquid to fill the balloon. Among the most used tubes, there are the BOTTON type tube, the gastrostomy balloon tube and the PEG tube.
According to Souza (SOUZA, 2011), the BOTTON gastrostomy tube is a great option for patients with neurological damage, behavioral disorders since its fixation is close to the patient's skin, making mechanical trauma almost impossible, however, since its fixation is directly on the skin, this model is presented in several sizes, this requires a previous analysis of the patient's condition to decide which size is suitable for each case.

The balloon gastrostomy tube for replacement or exchange is the best option since it's cost/effectiveness ratio has been increased when compared to other models (MANSUR, 2012). Although Foley ${ }^{\circledR}$ tubes have been widely used for this procedure, their viability has been declining, since the deterioration of latex by gastric acid is accelerated as well as patients may have adverse reactions due to unknown latex allergies. Again, balloon tube for replacement, even at a high price, have become the best option for patients in general.

Baskin (BASKIN, 2001) defends the use of tubes to perform percutaneous endoscopic gastrostomy (PEG) since this procedure is minimally invasive, it's material is specific and with resources that no other provides, it is the case of the massive and collapsible internal retainer, this probe does not allow reflux of gastric content as well as the diet, it's retainer is also used as anchoring the probe and on the outside there is the presence of the button that makes the tube impossible to progress to the stomach cavity.

\section{Discussion}

Several companies that manufacture medical equipment and material produce kits for primary percutaneous enteral access and exchange or replacement devices (EISEN et al 2002, BOSCO et al 2002, DALL'OSTO 2004, FANG 2006). Several changes in the structure, construction and use of materials in these kits have resulted in progressive evolution in terms of safety, cost-effectiveness, dissemination, efficiency, ease and simplicity of use (BASKIN 2001).

Among the various types of tubes used in gastrostomy, there is the BOTTON gastrostomy tube. Buttons are gastrostomy devices that 
are adapted to the level of the skin on the abdominal wall. They were developed by Gauderer and collaborators (Apud Gauderer, quoted by SOUZA, 2011) with the intention of avoiding the long length of the original gastrostomy tubes. This tube is short, the outer end is positioned close to the skin and its short external path allows greater comfort and prevents patients with altered state of consciousness from pulling and traumatically removing the tube. However, as they're not adjustable, they are available in various sizes, requiring prior assessment of the thickness of the stoma wall and lumen, in the gastrostomy tract, before placing the device (SOUZA, 2011) (Figure $1)$.

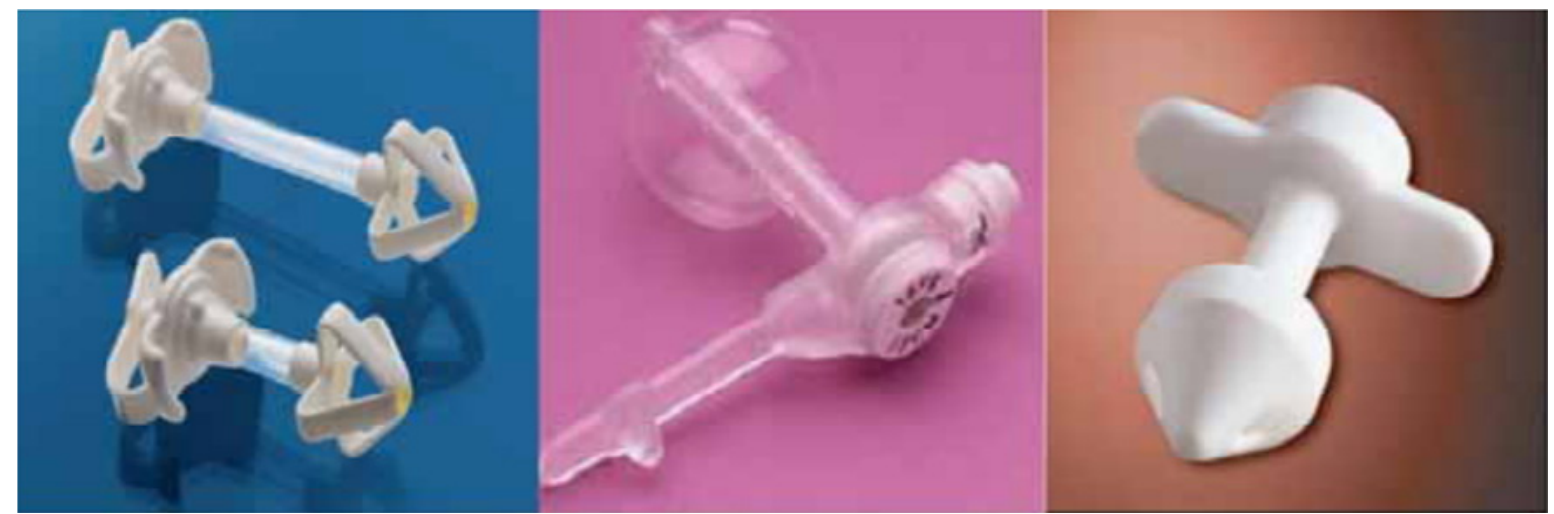

Figure I Models of gastrostomy buttons. On the left, enstristar (Kangoroo, Tyco, Kendall); in the center, MYC-KEY (Kimberly-Clark); and on the right, Passport (W.Cook).

Another model that can be used is the gastrostomy balloon tube for replacement or exchange. Gastrostomy can be used for a long period, so tubes with an inflatable balloon, used to replace the original tube, are obtained from several manufacturers. These replacement tubes have a large volume and high compliance balloon, inflatable with water. In addition, they come with an external retention disc with fixer and adapter terminal for the diet equipment. They're made of silicone with diameters ranging from 12 to $30 \mathrm{Fr}$. Although they still have a high price, their cost has been decreasing continuously, being currently considered very cost-effective mainly due to their greater durability. Some of the higher caliber tubes ( 28 and $30 \mathrm{Fr}$ ) allow the placement of jejunal extension tubes through their light (Figure 2), ${ }^{6,7}$

The tubes for carrying out PEG are basically produced from two types of material, silicone or polyurethane, with diameters ranging from 16 to $28 \mathrm{Fr}$ (EISEN et al 2002c, BOSCO et al 2002, FANG
2006). As a common feature, PEG tubes have an internal retainer whose basic purpose is to prevent accidental exit or removal of the probe. In addition, through its position against the anterior wall of the stomach, the retainer acts as a plug that prevents the extravasation of the diet and gastric secretions by the stoma. The structure of the internal retainers varies for each model, but the basic design is shaped like a dome, although they can be in the form of a flat disc, a triangular plate or a cage. Currently, the models available on the market feature, as a characteristic, the soft and collapsible internal retainer, allowing its removal by simple external traction, in an outpatient setting, generally endoscopic (or surgical) approach is no longer necessary to remove the gastrostomy tubes. As a contraindication to the use of PEG tubes, there are cases of previous abdominal surgery, hepatomegaly, ascites, gastric varices, abdominal mass and morbid obesity (Figure 3). ${ }^{8}$

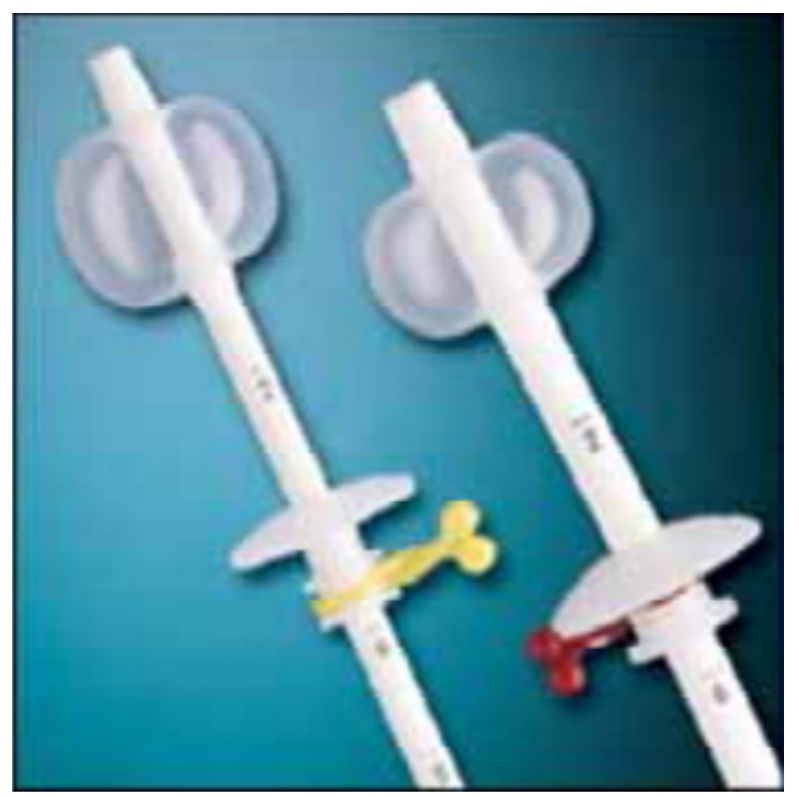

Figure 2 Models of replacement balloon tubes. On the left, BRT (W. Cook). 


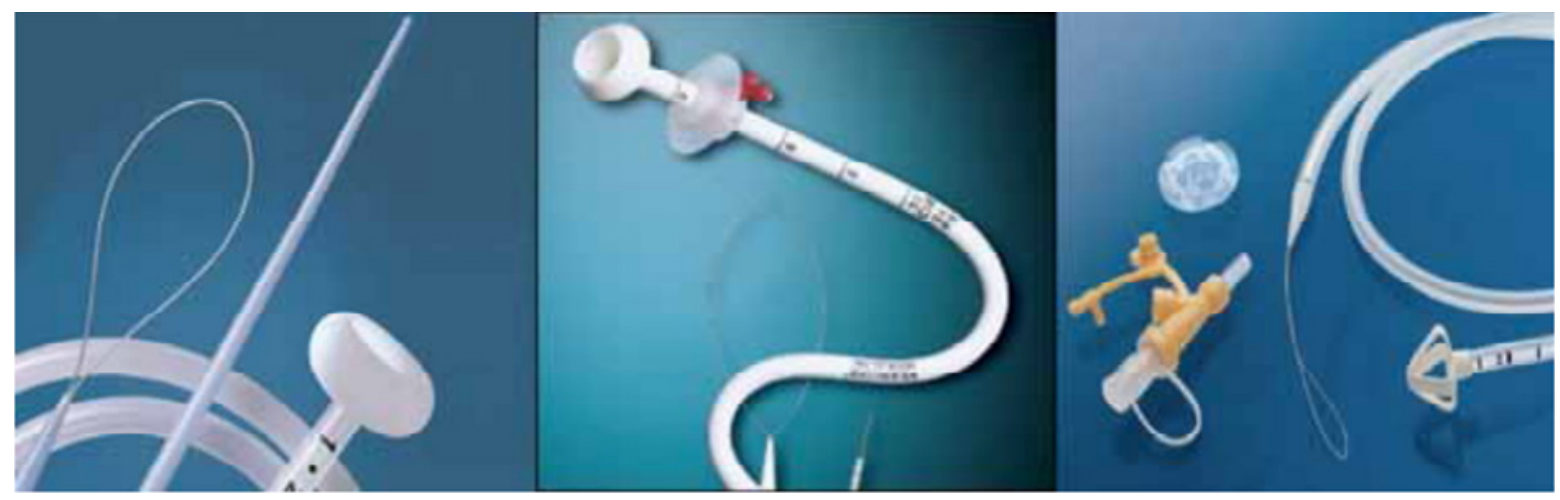

Figure 3 Models of PEG Kits. left, endo vive (Boston Scientific); in the center, PEG-24 Pull-S (W. Cook); and on the right, PEG Entristar (Tyco, Kendall).

\section{Conclusion}

After observing the three proposed tube models, it's evident that resources for maneuvers such as gastrostomies are largely decimated in current medicine. It should be remembered that the therapeutic decision to perform the gastrostomy procedure must always be supported by family members, professional ethics and the patient's real need. Given the peculiarities of each model, one can conclude that each case must be treated individually, that is, there is no gastrostomy tube more suitable for general use, there is the best possible tube for the specific case. This way, it is extremely important to have qualified and experienced professionals when deciding which is the best material for a specific procedure.

\section{Acknowledgments}

None.

\section{Conflicts of interest}

The authors declare have no conflict of interest about the publication of this paper.

\section{References}

1. Witzel O. Zur technik der magenfistulaeinlegung. Zbl Chir. 1891;18:601604.

2. Stamm M. Gastrostomy: a new method. Med News. 1894;65:324.

3. Grant JP. Comparison of percutaneous endoscopic gastrostomywith Stamm gastrostomy. Ann Surg. 1988;207(5):598-603.

4. Gauderer MW, Ponsky JL, Izant RJ Jr. Gastrostomy without laparoscopy: a percutaneous endoscopic technique. J Pediatr Surg. 1980;15(6):872-875.

5. Herman LL, Hoskins WJ, Shike M. Percutaneous endoscopic gastrostomy for decompression of the stomach and small bowel. Gastrointest Endosc. 1992;38(3):314-318.

6. Rohde, Luiz. Rotinas em cirurgia digestiva. 3. Porto Alegre ArtMed 2017.

7. Gastrostomia endoscópica percutânea - Técnicas e Aplicações. Publisher: Editora Rubio. 2012.

8. Delegge, Mark H, Gastrostomy tubes: Uses, patient selection, and efficacy in adults. UptoDate, c2020. 